\title{
Viskoz Sönümleyicilerin Burulma Düzensizliği Bulunan Çelik Yapılardaki Etkilerinin İncelenmesi
}

\author{
Murat HiçYILMAZ ${ }^{1 *}$, Mizan DOĞAN² ${ }^{2}$, Hasan GÖNEN ${ }^{3}$ \\ ${ }^{1}$ Afyon Kocatepe Üniversitesi, Mühendislik Fakültesi, Inş̧aat Mühendisliği Bölümü, Afyonkarahisar. \\ ${ }^{2,3}$ Eskişehir Osmangazi Üniversitesi, Mühendislik Mimarlık Fakültesi, İş̧aat Mühendisliği Bölümü, Eskişehir. mizan@ogu.edu.tr hgonen@ogu.edu.tr
ORCID ID: https://orcid.org/0000-0002-5718-3990
ORCID ID: https://orcid.org/0000-0002-5945-6956 \\ *Sorumlu Yazar e-posta: murathicyilmaz@aku.edu.tr ORCID ID: https://orcid.org/0000-0002-4132-4285
}

Geliş Tarihi: 30.05.2019; Kabul Tarihi: 13.11.2019

\begin{tabular}{|c|c|}
\hline & $\ddot{\partial} z$ \\
\hline $\begin{array}{c}\text { Anahtar kelimeler } \\
\text { Çelik yapılar; Viskoz } \\
\text { sönümleyiciler; } \\
\text { Burulma düzensizliği; } \\
\text { Zaman-tanım alanında } \\
\text { analiz }\end{array}$ & $\begin{array}{l}\text { Bir yapıyı burulma etkilerinden koruyabilmenin en iyi yolu, plan üzerinde yapının kütle ve rijitlik } \\
\text { merkezlerinin üst üste gelmesini sağlamaktır. Bu iki merkez arasındaki eksantrisiteden dolayı yapıda } \\
\text { burulma momenti etkileri ortaya çıkacaktır. Yapısal sönümleyiciler, sismik enerjinin büyük bir kısmını } \\
\text { sönümleyerek taşıyıcı sistem elemanlarının korunmasına yardımcı olurlar. Son yıllarda oldukça ilgi gören } \\
\text { pasif kontrol sistemleri, yapıların tasarım ya da güçlendirme çalışmalarında etkin olarak } \\
\text { kullanılmaktadırlar. Bu çalışmada pasif kontrol sistemlerinden viskoz sönümleyicilerin, burulma } \\
\text { düzensizliği bulunan çelik yapılar üzerindeki etkileri araştııımıştır. Bu amaçla planda düzensiz } \\
\text { (asimetrik) U ve L formda iki adet } 7 \text { katlı çelik yapı modeli tasarlanmıştır. Modeller üç farklı deprem } \\
\text { ivmesi altında zaman tanım alanında çözümlenmiş, sonuçlar sönümleyicisiz ve sönümleyici ilave edilmiş } \\
\text { durumlar için karşılaştııımıştır. Taşıyıc sistem rijitliği arttııılmaksızın viskoz sönümleyici ilavesinin, } \\
\text { modellerdeki burulma davranışını önemli ölçüde azalttığı gözlenmiştir. }\end{array}$ \\
\hline
\end{tabular}

\section{Investigation of the Viscous Damper Effects on Steel Structures with Torsional Irregularities}

\section{Keywords}

Steel Structure; Viscous dampers; Torsional Irregularity; Time-History Analyse

\begin{abstract}
The best way to protect a building from the effects of torsion is to make the center of mass and stiffness on top of the plan. Due to the eccentricity between these two centers, the torsional moment in the structure will emerge. Structural dampers help to protect the structural system elements by damping major portion of the seismic energy. In recent years passive control systems which are very popular, have been used effectively in the design or strengthening of buildings. In this study, the effects of viscous dampers on steel structures with torsional irregularities are investigated. For this purpose 7storey steel structure models are designed with $U$ and $L$ shaped on the planar. The models are solved in time history analyses under three different ground accelerations. The results are compared for two cases; without and with damper. Based on the results of time history analyses, it has been observed that the addition of the viscous damper considerably reduces the torsional behavior in the models without increasing the rigidity of the system.
\end{abstract}

(C) Afyon Kocatepe Üniversitesi

\section{Giriş}

Sismik izolasyon uygulamaları, taşıyıcı sistemlerin deprem, rüzgar vb. dış etkenlerden korunmasını geliştirmek için gün geçtikçe önemini arttıran bir konudur. Geleneksel yapılarda enerji malzemenin deformasyonu ile sönümlenmektedir. Viskoz sönümleyiciler, yapısal verimliliği arttırmanın alternatif bir yolunu sunmaktadır (Lee and Taylor 2001). Yapıya gelen dinamik kuvvetin neredeyse tüm enerjisi sönümleyiciler tarafından absorbe edilmektedir. Viskoz sönümleyiciler yapının doğrusal-elastik durumunun titreşimlere karşı 
korunmasını sağlamaktadır. Yapısal kuvvetler ve viskoz sönümleme kuvvetleri arasındaki $90^{\circ}$ faz farkı nedeniyle, viskoz sönümleyiciler yapının temel titreşim periyodunu değiştirmez (Constantinou vd. 1998). Yapılarda burulma düzensizliğinin ortaya çıkması için, yapının kütle merkezi ve rijitlik merkezi arasında bir eksantrisite bulunması gerekmektedir. $\mathrm{Bu}$ tür yapılar $\mathrm{X}$ ve $\mathrm{Y}$ doğrultularında ötelenme hareketine ek olarak, yapı düşey ekseni etrafında dönme davranışı da gösterirler. Eksantrisitenin ve yapıya etkiyen dinamik yüklerin derecesine bağlı olarak bu dönme davranışı, yapının büyük hasar almasına hatta yıkılmasına bile sebebiyet verebilir. Deprem Bölgelerinde Yapılacak Binalar Hakkında Yönetmelik'e göre (DBYYHY 2007) A1 burulma düzensizliği, birbirine dik iki deprem doğrultusunun herhangi biri için, herhangi bir katta en büyük göreli kat ötelemesinin o katta aynı doğrultudaki ortalama göreli ötelemeye oranını ifade eden burulma düzensizliği katsayı ile sınırlandırıımıştır.

Planda ve düşeyde ortaya çıkan düzensizlikler ve bunların önüne geçilebilmesi için sunulan çözümler birçok farklı araştırmacı tarafından incelenmiştir (Stefano ve Pintucchi 2008, Bosco vd. 2013). Lin ve Chopra (2001) simetrik olmayan yapıların simetrik yapılara kıyasla deprem kaynaklı hasarlara karşı daha savunmasız olduklarını ve bu hasarların viskoz sönümleyiciler eklenerek azaltılabileceğini belirtmişlerdir. Bir yapıyı burulma etkilerinden korumanın en iyi yolu plan üzerinde kütle ve rijitlik merkezlerini üst üste getirmektir. Fakat çeşitli sebeplerden dolayı bu her zaman mümkün olmaz. Deprem gibi dinamik yüklerin yapının ağırlık merkezine etkidiği ve bu yüklere tepki olarak ortaya çıkan atalet kuvvetlerinin de rijitlik merkezine etkidiği varsayılır. Bu iki merkez arasındaki eksantrisiteden dolayı yapıda burulma momenti ve taşıyıcı sistem elemanlarında ek kuvvetler ortaya çıkacağı bilinmektedir. Simetrik sistemler ile karşılaştırıldığında asimetrik sistemler, yatay etkiler altında yüksek deformasyona maruz kalmaktadır. Viskoz sönümleyicilerin asimetrik sistemlere eklenmesi deformasyonu azaltmaktadır. Goel (1998) tarafından yapılan çalışmada, asimetrik sistem deformasyonlarının uygun sönümleyici ilavesi ile simetrik bir sisteme eşit veya daha düşük bir seviyeye indirilebileceği belirtilmektedir. Landi vd. (2013) tarafından simetrik ve asimetrik betonarme binalara sönümleyici eklenerek sonuçlar karşılaştırılmış, daha yüksek mod katkısı göz önünde bulundurularak ve ötelenme modu yerine dönme modu dikkate alınarak daha kesin sonuçların elde edildiği belirtilmiştir. Mansoori ve Moghadam (2009) tarafından yapılan çalışmada, asimetrik çelik çerçevelerde viskoz sönümleyici etkileri üzerinde durulmuş, sönümleyici merkezinin kütle merkezinden rijitlik merkezine doğru hareket ettiğinde burulma etkilerinin azaldığı ve yanal yer değiştirmelerin arttığını gözlenmiştir. Derdiman ve Mirkelam (2011) tarafından planda düzensiz binaların deprem yükleri altında burulma davranışlarının incelendiği diğer bir çalışmada, farklı kat adedi ve sönüm özelliklerine sahip $L$ tipi binalar üzerinde zaman tanım alanında analizler yapılmıştır. Sonuç olarak tüm durumlarda taban kesme kuvvetlerinde bir iyileşme sağlandığı, burulma etkileri bakımından rijitlik merkezini kütle merkezine yaklaştıran sönümleyici yerleşimleri olumlu sonuç verdiği belirtilmiştir. Ebrahimi vd. (2017) plan düzensizliklerinin farklı sismik aktiviteye sahip bölgelerde bulunan çelik yapılarda oluşan göçme süreci üzerindeki etkisini araştırmışlardır. Doğrusal olmayan statik ve dinamik analizler neticesinde, düzensiz yapılardaki kolon talep kuvveti kapasite oranının, düzenli yapılara oranla ortalama 1.5 ila 2 kat fazla olduğu sonucuna ulaşılmıştır. Ulucan ve Alyamaç (2008) tarafından yapılan çalışmada, planda A3 türü yapısal düzensizliklere sahip çok katlı yapıların doğrusal olmayan deprem davranışı, rijit diyafram ve esnek diyafram kabulü ile ayrı ayrı incelenmiştir. Elde edilen sonuçlar arasında kayda değer bir farklılık olmadığı belirtilmiştir. Han vd. (2017) tarafından yapılan çalışmada çeşitli derecelerde burulma düzensizliği bulunan yapıların çökme performansları, zaman tanım alanında doğrusal olmayan analizler ile değerlendirilmiştir. Bununla birlikte göreli kat ötelenmesi tasarım taleplerinin hesaplanması için bir yöntem önerilmiştir. Işık vd. (2018) tarafından yapılan çalışmada, TBDY'ne göre burulma düzensizliğine sahip çelik yapılar itme analizine tabi tutulmuşlardır. Elde edilen sonuçlar hızlı değerlendirme yöntemi 
olarak seçilen Kanada Sismik Tarama Yöntemi ile karşılaştırılmıştır.

$\mathrm{Bu}$ çalışmada pasif kontrol sistemlerinden viskoz sönümleyicilerin, burulma düzensizliğine sahip çelik yapılar üzerindeki etkileri araştırılmıştır. Bu amaçla planda düzensiz (asimetrik) $U$ ve $L$ şeklinde iki adet 7 katlı çelik yapı modeli Deprem Bölgelerinde Yapılacak Binalar Hakkında Yönetmelik'e (DBYYHY 2007) uygun olarak tasarlanmıştır. Modeller 3 farklı deprem ivmesi altında zaman tanım alanında çözümlenmişlerdir. Kullanılan deprem ivmeleri Kocaeli (1999), Landers (1992) ve El Centro (1979)'dur. Bilindiği üzere deprem ivmeleri yapay olarak üretilerek ya da simüle edilerek yapısal analizlerde kullanılabilmekte, ayrıca gerçek deprem ivmelerinin ölçeklenerek kullanılması da bu bağlamda mümkün olmaktadır. Bu çalışmada gerçek deprem ivmelerinin kullanılmasının temel sebebi, yapay olarak üretilen deprem ivmelerinde gerçek üstü enerjinin ortaya çıkmasıdır. Bununla beraber gerçek ivme kayıtlarının deprem parametreleri (genlik, süre, frekans vb.) ile ilgili sağlıklı bilgiler içermesi ve sahanın sismolojik parametrelerini de göz önünde bulundurması diğer alternatiflere üstünlük sağlamaktadır (Fahjan 2008).

Sonuçlar, sönümleyicisiz ve sönümleyici ilave edilmiş durumlar için karşılaştırılarak, planda burulma etkilerinin hangi seviyeye kadar düşürüldüğü ortaya konulmaya çalışılmıştır. Taşıyıcı sistem rijitliği arttırılmaksızın viskoz sönümleyici ilavesinin, modellerdeki burulma davranışını önemli ölçüde azalttığı, bununla beraber taban kesme kuvveti ve iç kuvvet değerlerinde de önemli ölçüde düşüşe sebebiyet verdiği gözlenmiştir. Taşıyıcı sistemlere tasarım aşamasında ya da güçlendirme amacıyla sonradan ilave edilen yapısal sönümleyiciler, son yıllarda oldukça ilgi görmektedirler. Özellikle viskoz sönümleyicilerin, taşıyıcı sistem üzerinde hafif tahribatlar ile sisteme ilave edilebilmesi avantajlı bir durumdur. Büyük bir kısmı deprem riski altında yer alan ülkemizde, yapıların hızlı ve etkin bir şekilde rehabilitasyonu (sismik güçlendirme) bakımından viskoz sönümleyiciler göz önünde bulundurulması gereken sistemler olarak karşımıza çıkmaktadır.

\section{Materyal ve Metot}

\subsection{Kullanılan çelik yapı modelleri}

Bu çalışmada DBYYHY'e (2007) uygun olarak iki adet 7 katlı çelik yapı modeli tasarlanmıştır. Şekil 1'de Model U'ya ait, Şekil 2'de ise ve Model L'ye ait görünümler ve diyagonal sönümleyici dağılımları görülmektedir.

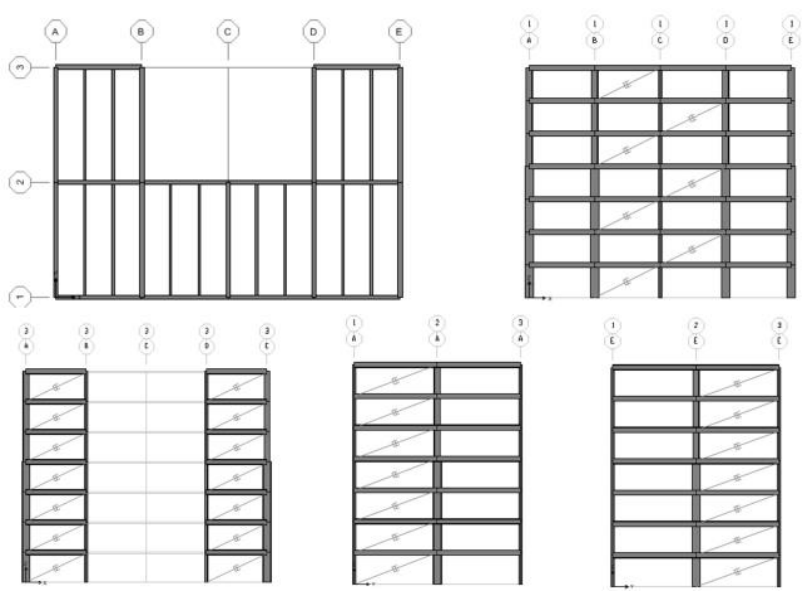

Şekil 1. Model U'ya ait görünüşler

Her iki modele etkiyen yayılı yükler, en üst katta 3.8 $\mathrm{kN} / \mathrm{m}^{2}$ sabit ve $1.0 \mathrm{kN} / \mathrm{m}^{2}$ hareketli, diğer katlarda ise $4.1 \mathrm{kN} / \mathrm{m}^{2}$ sabit ve $2.0 \mathrm{kN} / \mathrm{m}^{2}$ hareketli yük şeklindedir. A-E arası her bir aksın açıklığı $6 \mathrm{~m}$ olup toplam açıklık 24m, 1-3 arası her bir aksın açıklığı 8m ve toplam açıklık $16 \mathrm{~m}^{\prime}$ dir. Kat yüksekliği her katta eşit olup 3m, toplam yapı yüksekliği ise $21 \mathrm{~m}^{\prime}$ dir (Hiçyılmaz 2007). Taşıyıcı sistemler Fe52 yapı çeliğinden imal edilmiş olup elastisite modülü $210000 \mathrm{Mpa}$, poisson oranı 0.3, çekme gerilmesi $\sigma_{c}$ $=235 \mathrm{Mpa}$, akma gerilmesi $\sigma_{a}=360 \mathrm{Mpa}$ ve kayma emniyet gerilmesi $\tau_{\mathrm{em}}=122 \mathrm{Mpa}$ olarak alınmıştır. Her kat kendi içinde rijit diyafram olarak tanımlanmıştır. Hareketli yük katılım katsayısı 0.3, etkin yer ivmesi katsayısı 0.3 (2. derece deprem bölgesi), bina önem katsayısı 1.0, taşıyıcı sistem davranış katsayısı 8 (Süneklik düzeyi yüksek sistem), yerel zemin sınıfı Z4 (Spektrum karakteristik periyotları $\mathrm{T}_{\mathrm{a}}=0.20, \mathrm{~T}_{\mathrm{b}}=0.90$ ) olarak tanımlanmıştır. Analizler SAP2000 (2014) yapısal analiz programında yapılmıştır. 


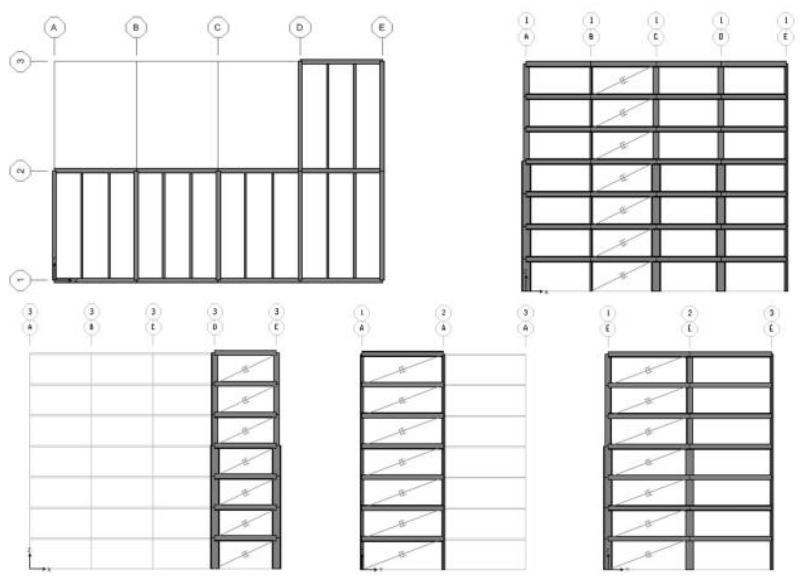

Şekil 2. Model L'ye ait görünüşler

TS500 (2000) ve DBYYHY'te (2007) verilen 41 adet yükleme kombinasyonuna bağlı olarak elde edilen iç kuvvetler neticesinde Model U ve Model L kolon ve kirişlerinde kullanılması uygun görülen kesitler Çizelge 1'de verilmiştir.

Çizelge 1. Analizler neticesinde seçilen kesitler

\begin{tabular}{|c|c|c|c|}
\hline Kat Seviyesi & Kolonlar & Ana kirişler & İkincil kirişler \\
\hline 7 & & \multirow{7}{*}{ HE500B } & \multirow{7}{*}{ IPE330 } \\
\hline 6 & HE600B & & \\
\hline 5 & & & \\
\hline 4 & \multirow{4}{*}{ HE800B } & & \\
\hline 3 & & & \\
\hline 2 & & & \\
\hline 1 & & & \\
\hline
\end{tabular}

Çizelge 2'de ise enkesit ölçüleri sunulmaktadır.

Çizelge 2. Enkesit ölçüleri

\begin{tabular}{ccccccc}
\hline & $\mathbf{h}$ & $\mathbf{b}$ & $\mathbf{t}_{\mathbf{w}}$ & $\mathbf{t}_{\mathbf{f}}$ & $\mathbf{r}$ \\
Enkesit & $\mathrm{mm}$ & $\begin{array}{c}\mathrm{m} \\
\mathrm{m}\end{array}$ & $\mathrm{mm}$ & $\mathrm{mm}$ & $\mathrm{m}$ \\
\hline IPE 330 & 330 & 160 & 7.5 & $\begin{array}{c}11 . \\
5\end{array}$ & 18 \\
\hline HE 500 B & 500 & 300 & $\begin{array}{c}14 . \\
5\end{array}$ & 28 & 27 \\
\hline HE 600 B & 600 & 300 & $\begin{array}{c}15 . \\
5\end{array}$ & 30 & 27
\end{tabular}

\subsection{Zaman-Tanım Alanında Analiz}

Yapıların yer ivmesi altındaki davranışının belirlenmesi için zaman tanım alanında doğrusal dinamik analizler yapılmıştır. Toplam üç adet deprem verisi kullanılmıştır. Analizlerde P-delta etkileri dikkate alınmıştır ve Newmark sayısal integrasyon yöntemi kullanılmıştır. Integrasyon parametreleri $\beta=0.25$ ve $\gamma=0.50$ (sabit ivme) olarak seçilmiştir. Yapısal sönüm matrisinin hesabında Rayleigh sönümü kullanılmıştır.

\subsection{Yer ivmeleri}

Bu uygulamada Fahjan (2008) tarafından yapılan çalışmada elde edilen, ölçeklendirilerek deprem yönetmeliğinde verilen tasarım spektrumuna uygun hale getirilmiş üç adet deprem kaydı kullanılmıştır. Şekil 3'te kullanılan deprem kayıtları ve spektral ivme-zaman grafikleri görülmektedir.
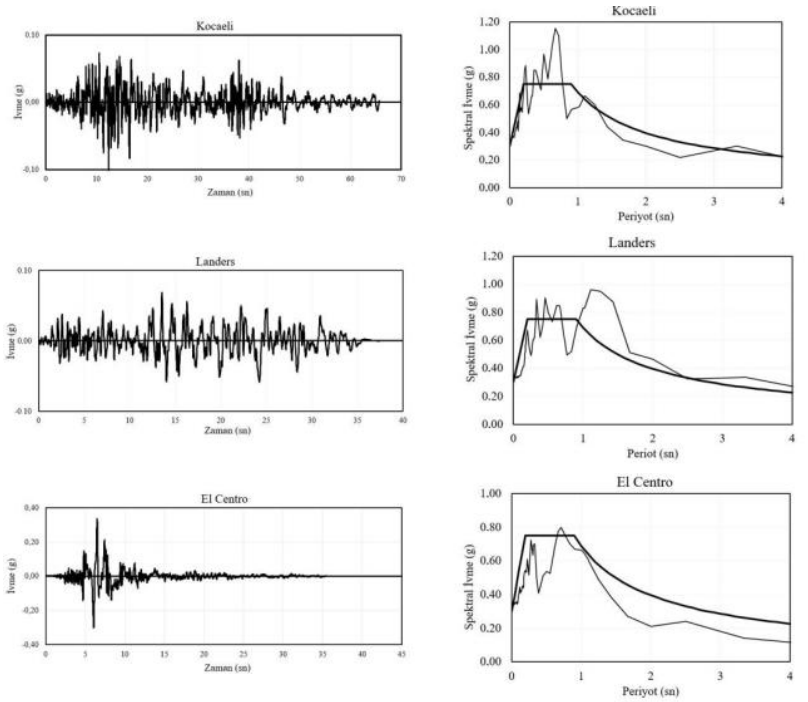

Şekil 3. Ölçeklendirilmiş spektral ivme-zaman grafikleri

Pasifik Dep. Müh. Arş. Merkezi'nden (PEER 2006) alınan ivme kayıtlarına ait detaylar Çizelge 3'te verilmiştir.

Çizelge 3. Yer ivmesi kayıtları

\begin{tabular}{cccccc}
\hline Deprem & Tarih & İstasyon & Kayıt & $\begin{array}{c}\text { Süre } \\
\text { (sn) }\end{array}$ & Ölçek \\
\hline Kocaeli & $17 / 08 / 99$ & Bursa Tofaş & BUR000 & 57.2 & 11.63 \\
\hline Landers & $28 / 06 / 92$ & $\begin{array}{c}\text { Fountain } \\
\text { Valley }\end{array}$ & EUC292 & 38.5 & 16.16 \\
\hline $\begin{array}{c}\text { EI } \\
\text { Centro }\end{array}$ & $15 / 10 / 79$ & $\begin{array}{c}5028 \\
\text { EcArray\#7 }\end{array}$ & $\begin{array}{c}\text { E07230 } \\
\text { E07230 }\end{array}$ & 36.8 & 2.69 \\
\hline
\end{tabular}

\subsection{Rayleigh sönümü yaklaşımı}

Çelik modellerin içsel sönüm hesabı için Rayleigh sönümü yaklaşımı kullanılmıştır. $m$ ve $k$ sırasıyla mekanik titreşim sisteminin kütle ve rijitlik matrisleri ve $\alpha, \beta$ sabit sayılar olmak üzere Rayleigh Sönüm Modelinde doğal sönüm matrisi Denklem 1 ile hesaplanmaktadır. 


$$
\mathrm{C}=\alpha[\mathrm{M}]+\beta[\mathrm{K}]
$$

Birinci ve ikinci moda ait sönüm oranları birbirine eşit alınacak olursa $\left(\xi_{i}=\xi_{j}=\xi\right), \alpha$ ve $\beta$ katsayıları Denklem 2 ile hesaplanabilmektedir.

$$
\alpha=\xi \frac{2 \omega_{i} \omega_{j}}{\omega_{i}+\omega_{j}}, \quad \beta=\xi \frac{2}{\omega_{i}+\omega_{j}}
$$

Modellerde ilk iki moda ait sönüm oranları birbirine eşit ve $\xi_{i}=\xi_{j}=0.03$ olarak alınmıştır. Model U'ya ait ilk iki mod açısal frekans değerleri $\omega_{1}=5.736, \omega_{2}=6.152$ olduğundan $\alpha=0.178$ ve $\beta=0.00505$, Model L'ye ait ilk iki mod açısal frekans değerleri $\omega_{1}=5.840$, $\omega_{2}=6.427$ olduğundan $\alpha=0.184$ ve $\beta=0.00489$ olarak hesap edilmiştir.

\subsection{Sönümleyici katsayısı hesabı}

Doğrusal sönümleyiciler için sönümleyici katsayısı hesabı (efektif sönüm oranı) FEMA273 (1997) şartnamesinden alınmıştır.

$$
\xi_{\mathrm{eff}}=\xi+\frac{\mathrm{T} \sum \mathrm{C}_{\mathrm{j}} \cdot \alpha^{2} \cdot\left(\emptyset_{\mathrm{j}}-\emptyset_{\mathrm{j}-1}\right)^{2}}{4 \pi \sum_{1}^{7} \mathrm{~m}_{\mathrm{i}} \emptyset_{\mathrm{i}}^{2}}
$$

Denklem 3'te verilen; $\xi_{\text {eff }}$ efektif sönüm oranı, $\xi$ sistem sönüm oranı, $T$ birinci doğal titreşim periyodu, $C_{j}$ sönüm elemanı sönüm katsayısı, $m_{i}$ kat kütlesi, $\emptyset_{\mathrm{j}}$ j. kat 1. mod deplasman değerleri ve $\alpha$ sönümleyici tipine bağlı katsayıdır. Sönümleyiciler her kata birer adet olacak şekilde (üniform), orta açıklığa ve diyagonal olarak yerleştirilmiştir. Tüm modeller için birinci mod içsel sönüm oranı \% 3, toplam efektif sönüm oranı ise \% 8 ve \% 20 olarak seçilmiştir. Buna göre, Model $U$ için üniform dağılımda hedef sönüm oranlarını sağlayacak sönümleyici katsayıları hesap detayı Çizelge 4'te

\begin{tabular}{|c|c|c|c|c|c|c|}
\hline$\emptyset_{1}$ & $\Delta \emptyset_{1}$ & $\begin{array}{c}\mathrm{m}_{\mathrm{i}} \\
\left(\mathrm{kNsn^{2 } / \mathrm { m }}\right. \\
)\end{array}$ & $\begin{array}{c}T_{1}(s n \\
1\end{array}$ & $\alpha$ & $\alpha^{2}\left(\Delta \emptyset_{1}\right)^{2}$ & $m_{i}\left(\varnothing_{1}\right)^{2}$ \\
\hline 0.0364 & 0.0029 & \multirow{2}{*}{158} & \multirow{6}{*}{1.09} & \multirow{6}{*}{$\begin{array}{c}0.89 \\
4\end{array}$} & 0.00000 & 0.2113 \\
\hline 8 & 4 & & & & 6 & 3 \\
\hline 0.0335 & 0.0046 & \multirow{2}{*}{205} & & & 0.00001 & 0.2314 \\
\hline 4 & 1 & & & & 7 & 8 \\
\hline 0.0289 & 0.0062 & \multirow{2}{*}{205} & & & 0.00003 & 0.1721 \\
\hline 3 & 9 & & & & 1 & 7 \\
\hline
\end{tabular}
görülmektedir.

Çizelge 4. Sönümleyici katsayısı hesabı (Model U-X Yönü)

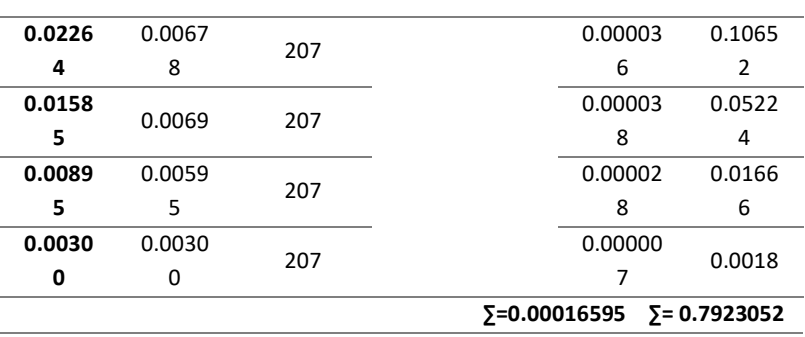

Model U X yönü için sönümleyici katsayıları Denklem 4 ile hesaplanmıştır.

$$
\begin{aligned}
& \mathrm{C}_{0.08}=\frac{(0.08-0.03) 4 \pi 0.7923052}{1.090 .00016595}=2742 \frac{\mathrm{kNsn}}{\mathrm{m}} \\
& \mathrm{C}_{0.20}=\frac{(0.20-0.03) 4 \pi 0.7923052}{1.090 .00016595}=9321 \frac{\mathrm{kNsn}}{\mathrm{m}}
\end{aligned}
$$

\begin{tabular}{|c|c|c|c|c|c|c|}
\hline$\emptyset_{1}$ & $\Delta \emptyset_{1}$ & $\begin{array}{c}\mathrm{m}_{\mathrm{i}} \\
\left(\mathrm{kNsn^{2 } / \mathrm { m }}\right. \\
)\end{array}$ & $\begin{array}{l}\mathrm{T}_{1}(\mathrm{sn} \\
1\end{array}$ & $\alpha$ & $\alpha^{2}\left(\Delta \emptyset_{1}\right)^{2}$ & $m_{i}\left(\emptyset_{1}\right)^{2}$ \\
\hline 0.0456 & 0.0036 & \multirow{2}{*}{132} & \multirow{14}{*}{1.08} & \multirow{14}{*}{$\begin{array}{l}0.93 \\
6\end{array}$} & 0.00001 & 0.27618 \\
\hline 5 & 4 & & & & 1 & 4 \\
\hline 0.0420 & 0.0057 & \multirow{2}{*}{171} & & & 0.00002 & 0.30294 \\
\hline 1 & 5 & & & & 9 & 9 \\
\hline 0.0362 & 0.0078 & \multirow{2}{*}{171} & & & 0.00005 & 0.22569 \\
\hline 6 & 6 & & & & 4 & 9 \\
\hline 0.0283 & 0.0085 & \multirow{2}{*}{173} & & & 0.00006 & 0.13986 \\
\hline 9 & 1 & & & & 3 & 1 \\
\hline 0.0198 & 0.0086 & \multirow{2}{*}{173} & & & 0.00006 & 0.06857 \\
\hline 8 & 6 & & & & 5 & 4 \\
\hline 0.0112 & 0.0074 & \multirow{2}{*}{173} & & & 0.00004 & 0.02184 \\
\hline 2 & 7 & & & & 8 & 5 \\
\hline 0.0037 & 0.0037 & \multirow{2}{*}{173} & & & 0.00001 & 0.00244 \\
\hline \multirow[t]{3}{*}{5} & 5 & & & & 2 & 1 \\
\hline & & & & & \multicolumn{2}{|c|}{$\Sigma=0.00028525$} \\
\hline & & & & & & $=1.037557$ \\
\hline
\end{tabular}

Aynı şekilde Model Y için üniform dağılımda hedef sönüm oranlarını sağlayacak sönümleyici katsayıları hesap detayı Çizelge 5'te görülmektedir.

Çizelge 5. Sönümleyici katsayısı hesabı (Model L-Y Yönü)

Model L Y yönü için sönümleyici katsayıları ise Denklem 5 ile hesaplanmıştır.

$$
\begin{aligned}
& C_{0.08}=\frac{(0.08-0.03) 4 \pi 1.037557}{1.080 .00028525}=2116 \frac{\mathrm{kNsn}}{\mathrm{m}} \\
& \mathrm{C}_{0.20}=\frac{(0.20-0.03) 4 \pi 1.037557}{1.080 .00028525}=7195 \frac{\mathrm{kNsn}}{\mathrm{m}}
\end{aligned}
$$

Yukarıda verilen denklemlere bağlı olarak hesaplanan sönümleyici katsayıları, Çizelge 6'da toplu olarak verilmiştir.

Çizelge 6. Tüm durumlar için hesaplanan sönümleyici katsayıları (kN sn/m) 


\begin{tabular}{lccc}
\hline & $\xi_{\text {eff }}$ (\%) & X Yönü & Y Yönü \\
\hline \multirow{2}{*}{ Model U } & 8 & 2742 & 2970 \\
\cline { 2 - 4 } & 20 & 9321 & 10094 \\
\hline \multirow{2}{*}{ Model L } & 8 & 2606 & 2116 \\
\cline { 2 - 4 } & 20 & 8860 & 7195 \\
\hline
\end{tabular}

\subsection{Burulma düzensizliği}

Bir yapıda burulma düzensizliğinin ortaya çıkması için, yapının kütle merkezi ve rijitlik merkezi arasında bir eksantrisite bulunması gerekir. Bu tür yapılar X ve $Y$ doğrultularında ötelenme hareketine ek olarak, yapı düşey ekseni etrafında dönme davranışı da gösterirler. Eksantrisitenin ve yapıya etkiyen dinamik yüklerin derecesine bağlı olarak bu dönme davranışı, yapının büyük hasar almasına, hatta yıkılmasına bile sebebiyet verebilir. Bu yüzden IBC06 (2006), UBC97 (1997) ve ASCE7-10 (2010) vb. birçok çağdaş deprem yönetmeliğinde burulma davranışının göz önüne alınması için yaptırımlar vardır. DBYYHY (2007)'de A1 burulma düzensizliği; birbirine dik iki deprem doğrultusunun herhangi biri için, herhangi bir katta en büyük göreli kat ötelemesinin o katta aynı doğrultudaki ortalama göreli ötelemeye oranını ifade eden burulma düzensizliği katsayı $\eta_{b i}>1.2$ olması durumudur. Bu katsayı Denklem 6'da verilmiştir. Göreli kat ötelemelerinin hesabı, $\pm \% 5$ ek dışmerkezlik etkileri de göz önüne alınarak yapılır.

$$
\eta_{\mathrm{bi}}=\Delta_{\text {imax }} / \Delta_{\text {iort }}>1.2
$$

\section{Bulgular}

$U$ ve L planlı çelik yapılar üzerinde her iki yönde sönümleyicisiz ve sönümleyicili durumlar için zaman tanım alanında doğrusal analizler gerçekleştirilmiştir. $\mathrm{Bu}$ analizler neticesinde, sönümleyici ilavesinin ve sönüm oranının yapıların davranışlarında ne gibi iyileşmeler sağladığı anlaşılmaya çalışılmıştır. Şekil 4'te her iki modele ait (ilk üç mod için) mod şekilleri görülmektedir.

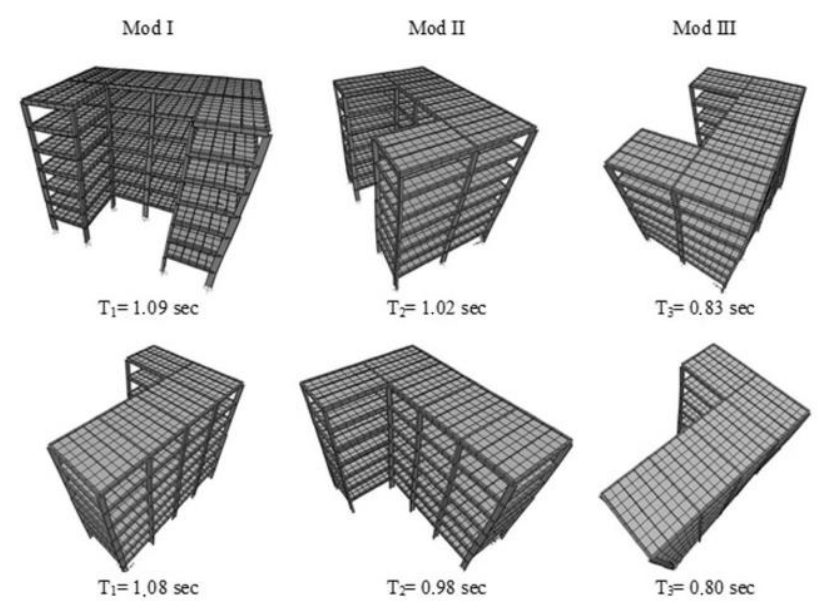

Şekil 4. Her iki modele ait ilk üç mod şekli

Şekil 5'te, analizlerde kullanılan üç adet deprem kaydı için hesaplanan burulma düzensizliği katsayıları $\left(\eta_{\text {bi }}\right)$ verilmiştir. Model $U^{\prime}$ da $X$ yönünde, Model L'de ise $Y$ yönünde burulma etkileri gözlendiğinden, sadece ilgili yönlerdeki veriler sunulmuştur.
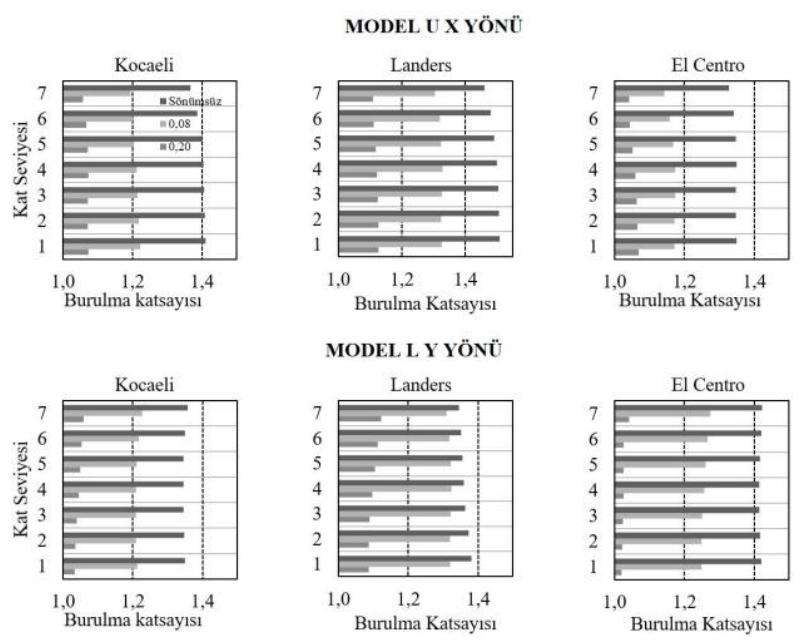

Şekil 5. Her iki modele ait burulma katsayıları $\left(\eta_{b i}\right)$

Şekil 5'te görüldügü üzere, planda düzensiz taşıyıcı sisteme sahip yapılarda burulma etkilerinin ortaya çıkması kaçınılmazdır. Her iki modelde de sönümleyicisiz durumda burulma katsayıları deprem yönetmeliğinde verilen 1.2 üst limit değerini aşmıştır. $\xi=0.08$ sönüm oranında, Model U sadece EI Centro ivme kaydı için limit değerin altında kalmıştır. $\xi=0.20$ sönüm oranı için tüm değerler üst limit değerinin altında kalmış olup burulma etkileri sönümleyiciler vasıtasıyla ortadan kaldırılmıştır. 

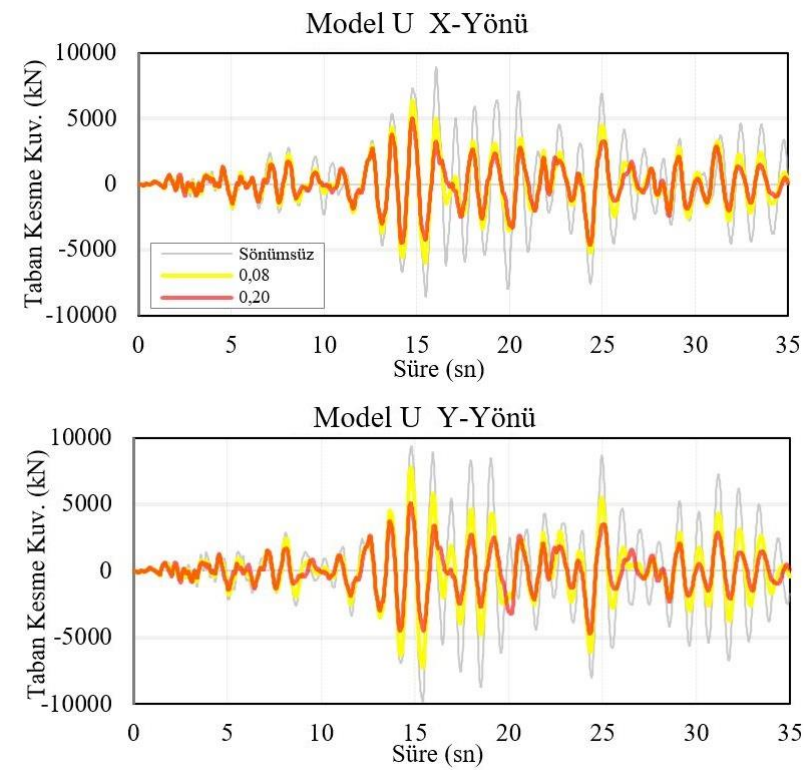

Şekil 6. Model U için taban kesme kuvveti-süre

Şekil 6'da Model U için, Şekil 7'de ise Model L için taban kesme kuvveti-süre ilişkileri verilmiştir. Viskoz sönümleyicilerin modellere ilave edilmesi ile her iki modelin her iki yönü için taban kesme kuvvetlerinde düşüş gözlenmiştir.
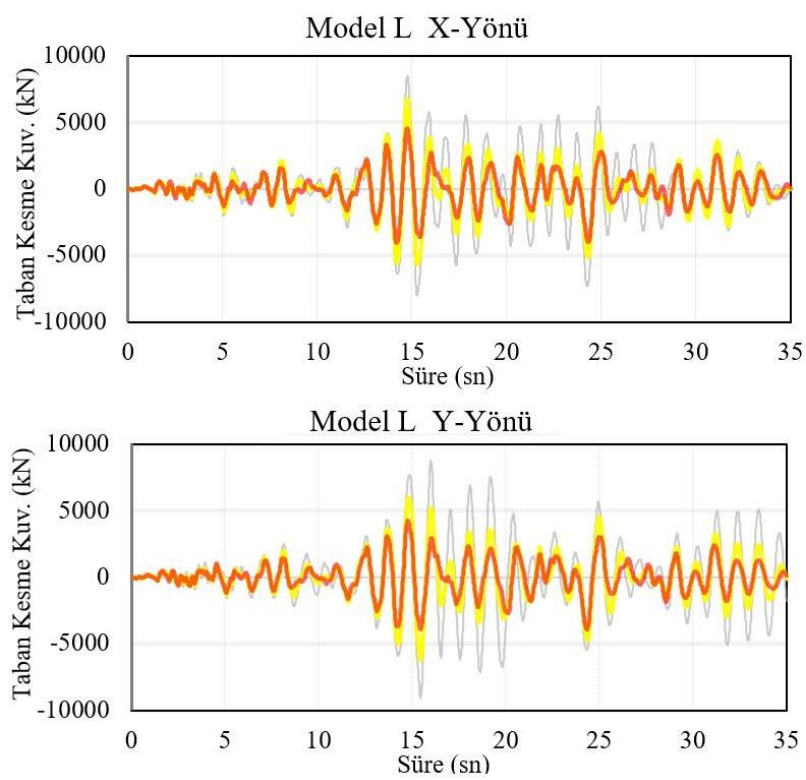

Şekil 7. Model L için taban kesme kuvveti-süre

Şekil 8'de modellerde oluşan en büyük taban kesme kuvvetleri verilmiştir. Taban kesme kuvvetlerindeki düşüş oranı ile ilgili olarak, ne aynı modelin $X$ ve $Y$ yönlerinde, ne de iki model arasında anlamlı bir bağımlılık görülmemiştir. Örnek vermek gerekirse, Landers yer ivmesi altında Model $U$ 'da $X$ yönünde oluşan taban kesme kuvvetlerindeki düşüş yüzdesi, sönümsüz duruma göre, 0.08 ve $0.20^{\prime}$ lik sönüm oranları için sırasıyla \% 28.8 ve

$\% 44.2$ iken, $\mathrm{El}$ Centro yer ivmesi altında bu değerler \% 15.7 ve \% 23.4 olarak bulunmuştur. Oysa Model L'de bu değerler Landers yer ivmesi altında \% 31.3 ve \% 53.2'ye kadar yükselmiştir.
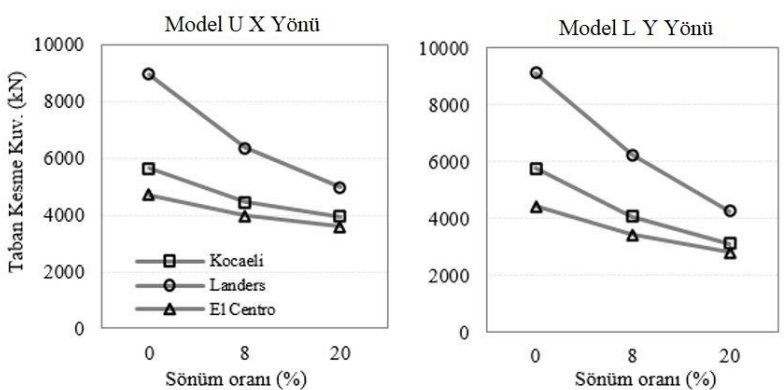

Şekil 8. Taban kesme kuvveti değerleri

Analizlerden elde edilen diğer bir sonuç z ekseni etrafında oluşan burulma momenti değerleri olup Şekil 9'da verilmiştir. Model U için X yönünde, Model $Y$ için ise $Y$ yönünde burulma etkileri gözlendiğinden sadece bu yönlere ait sonuçlar değerlendirilmiştir. Model $U$ ele alınacak olursa, tüm yer ivmeleri için elde edilen sonuçlar birbirine oldukça yakın çıkmıştır. Aynı sonuç Model Y için de söylenebilir. Bununla beraber, taban kesme kuvveti değerlerinde elde edilenlerden farklı olarak, burulma momentinde sönümleyici ilavesiyle elde edilen düşüş oranı, 0.08 ve $0.20^{\prime}$ lik sönüm oranları için her iki modelde de sırasıyla \% 50 ve \% 80 mertebesinde olmuştur.
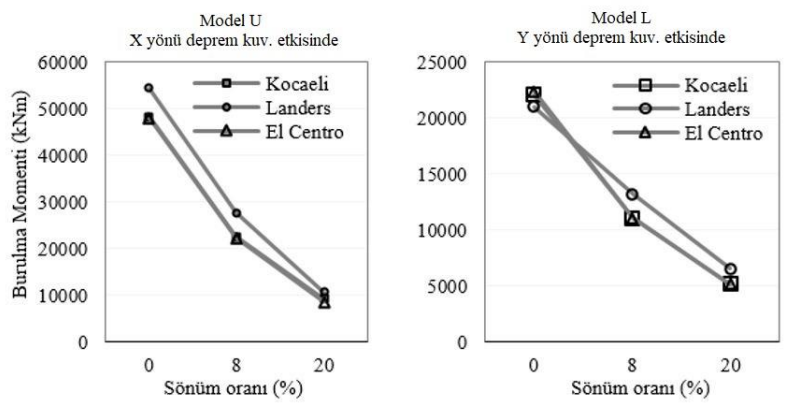

Şekil 9. Taban burulma momenti değerleri

Şekil 10'da Model U'nun kolonlarında, X yönünde, üç adet yer ivmesi altında oluşan en büyük göreli kat ötelenme oranı, eksenel kuvvet, kesme kuvveti ve eğilme momenti değerlerinin ortalama değerleri görülmektedir. X yönünde 0.08 ve 0.20 sönüm oranları için göreli kat ötelenme oranı sırasıyla yaklaşık \% 41 ve \% 65'lik bir düşüş göstermiştir. Kesme kuvveti ve eğilme momenti değerleri için ise sonuçlar birbirine yakındır ve yaklaşık $\% 40$ ve $\% 55$ mertebesindedir. Eksenel kuvvetlerdeki düşüş oranı ise yaklaşık olarak \% 19 ve \% 33 mertebesindedir. 

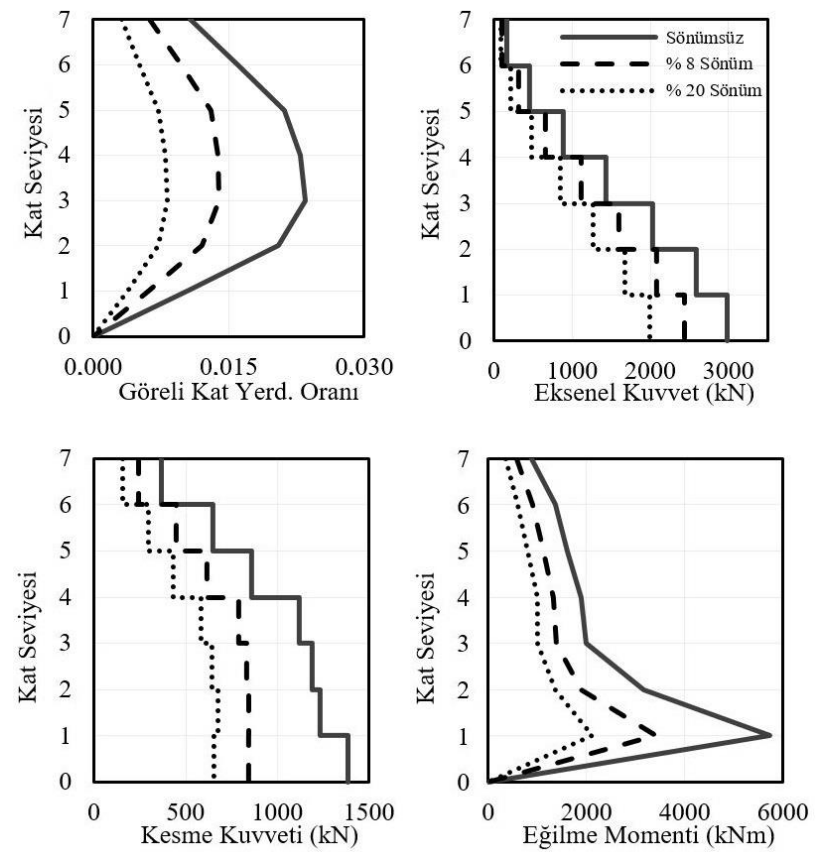

Şekil 10. Kolonlarda oluşan en büyük iç kuvvet değerleri (Model U X Yönü)

Şekil $11^{\prime}$ de ise Model U'nun kolonlarında, Y yönünde, üç adet yer ivmesi altında oluşan en büyük göreli kat ötelenme oranı, eksenel kuvvet, kesme kuvveti ve eğilme momenti değerlerinin ortalama değerleri görülmektedir. $Y$ yönünde tüm değerler 0.08 sönüm oranı için yaklaşık \% $25,0.20$ sönüm oranı için ise \% 52 mertebesinde bir düşüş göstermişlerdir. $Y$ yönünde tüm değerlerin aynı oranda düşme eğilimi göstermesinin sebebinin yapının bu yönde simetrik oluşundan ileri geldiği düşünülmektedir.
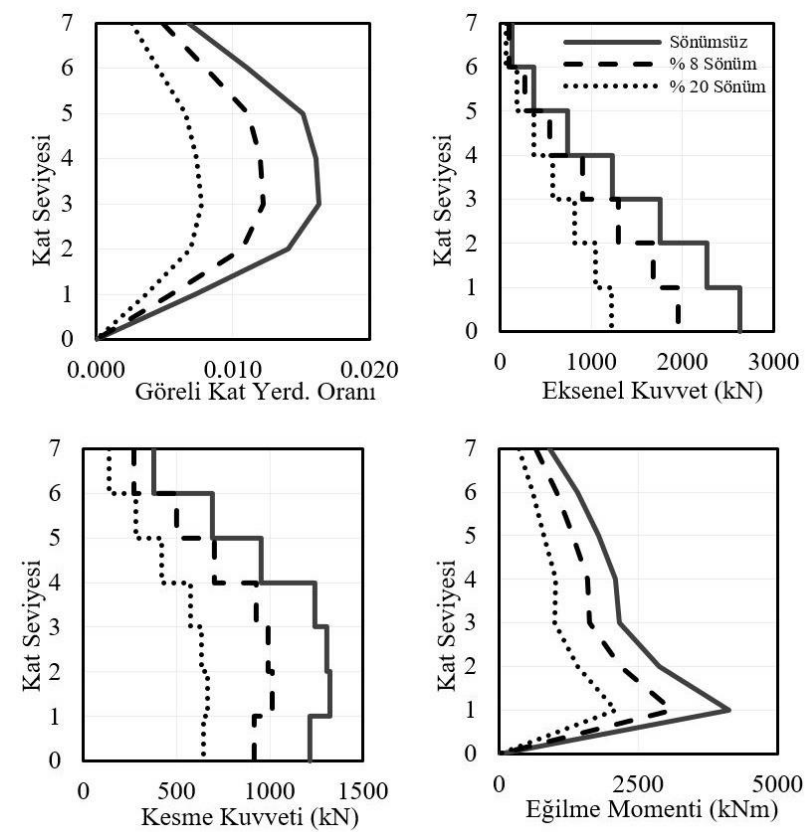

Şekil 11. Kolonlarda oluşan en büyük iç kuvvet değerleri (Model U Y Yönü)
Şekil 12'de Model L'nin kolonlarında, X yönünde, üç adet yer ivmesi altında oluşan en büyük göreli kat ötelenme oranı, eksenel kuvvet, kesme kuvveti ve eğilme momenti değerlerinin ortalama değerleri görülmektedir.
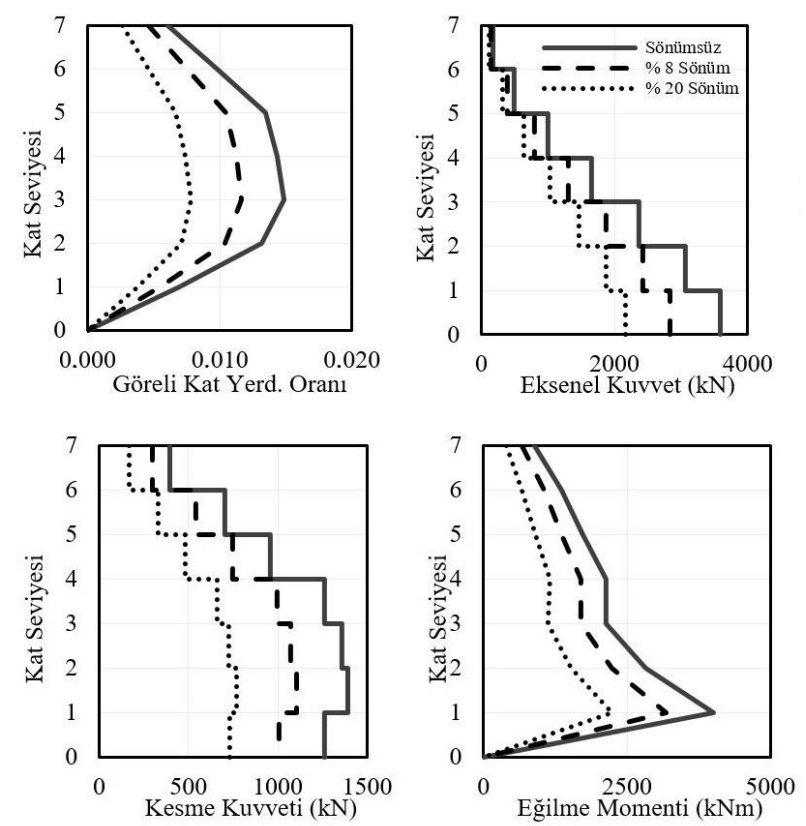

Şekil 12. Kolonlarda oluşan en büyük iç kuvvet değerleri (Model L X Yönü)

Tüm iç kuvvet değerleri artan sönüm oranları ile düşüş göstermişlerdir. $X$ yönünde tüm değerler 0.08 sönüm oranı için yaklaşık \% $20,0.20$ sönüm oranı için ise \% 44 mertebesinde bir düşüş göstermişlerdir. $\mathrm{Bu}$ sonuç Model $U^{\prime}$ da $Y$ yönünde elde edilen sonuçlar ile benzerlik göstermektedir. Şekil 13'de ise Model L Y yönüne ait değerler görülmektedir.
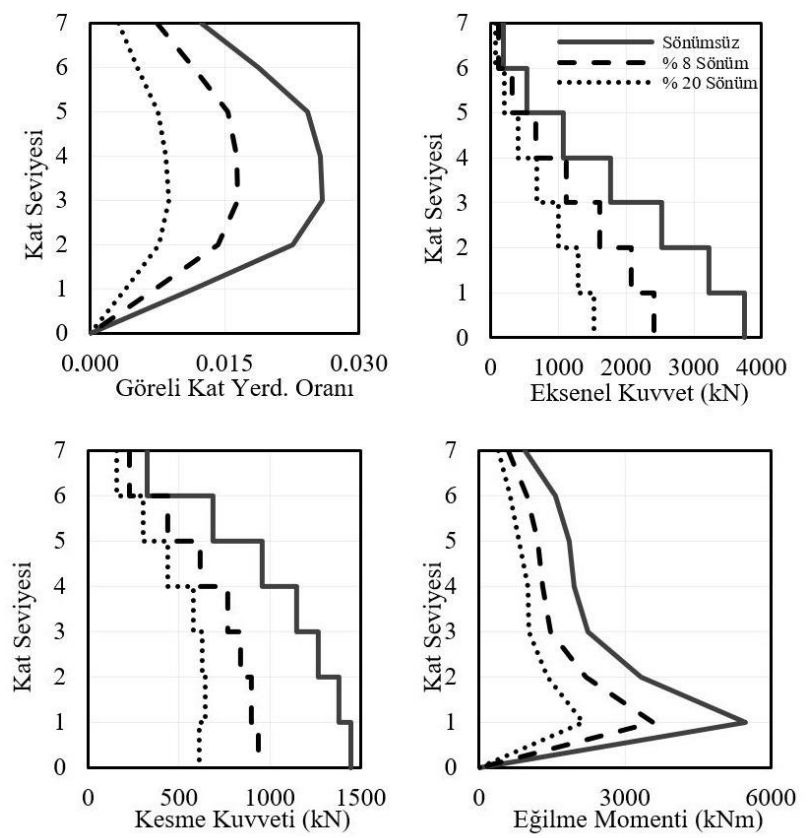

Şekil 13. Kolonlarda oluşan en büyük iç kuvvet değerleri (Model L Y Yönü) 
Model L'nin kolonlarında, Y yönünde, üç adet yer ivmesi altında oluşan en büyük göreli kat ötelenme oranı, eksenel kuvvet, kesme kuvveti ve eğilme momenti değerlerinin ortalama değerlerine bakıldığında, 0.08 ve 0.20 sönüm oranları için tüm iç kuvvet değerlerinde sırasıyla yaklaşık \% 36 ve \% $66^{\prime}$ lık bir düşüş gözlenmiştir. Böylelikle, incelenen iç kuvvet değerlerinde, taban burulma momenti ve taban kesme kuvveti değerlerinde sönümleyici ilavesine bağlı olarak belli mertebelerde iyileşmeler sağlandığı söylenebilir.

\section{Tartışma ve Sonuç}

Bu çalışmada planda burulma düzensizliği bulunan iki adet 7 katlı çelik yapı modeli tasarlanmış ve viskoz sönümleyici ilavesi ile bu düzensizliklerin ortadan kaldırılması hedeflenmiştir. Her iki modelde de sönümleyicisiz durumda burulma katsayıları üst limit değerini aşmıştır. $\xi=0.08$ sönüm oranında, Model $U$ sadece El Centro ivme kaydı için limit değerin altında kalmıştır. $\xi=0.20$ sönüm oranı için tüm değerler üst limit değerinin altında kalmış olup burulma etkileri sönümleyiciler vasıtasıyla ortadan kaldırılmıştır. Taban kesme kuvvetlerindeki düşüş oranı ile ilgili olarak, ne aynı modelin $X$ ve $Y$ yönlerinde, ne de iki model arasında anlamlı bir bağımlılık görülmemiştir. Artan sönüm oranıyla beraber tüm yer ivmeleri için taban kesme kuvvetlerinde belirgin bir düşüş gözlenmiştir. Taban kesme kuvvetleriyle beraber burulma momenti değerlerinde de, 0.08 ve $0.20^{\prime}$ lik sönüm oranları için, her iki modelde de sırasıyla $\% 50$ ve $\% 80$ mertebesinde düşüş gözlenmiştir. İki farklı sönüm oranı için her iki modelde, en büyük göreli kat ötelenme oranı, kat eksenel kuvveti, kesme kuvveti ve eğilme momenti değerlerinde sönümleyicisiz duruma göre önemli bir iyileşme sağlanmıştır. Bu veriler ışığında, planda burulma etkilerini önleyecek şekilde konumlandırılan viskoz sönümleyicilerin, öncelikli olarak kat deplasman değerlerini ve buna bağlı olarak kat kolonlarında oluşan iç kuvvet değerleri ve yapıda ağırlık merkezi ile rijitlik merkezi kaçıklığından kaynaklanan burulma momentlerini belli oranlarda azaltarak, yapıların sismik performansını arttırıcı bir etkiye sahip olduğu söylenebilir. Yapıya ilave edilen sönümleyici ebatları seçilirken, ortadan kaldırılması istenilen sismik olumsuzluğun derecesine bağlı olarak hesap yapmak gerekir. Zira bu çalışmada öncelikle seçilen 0.08 sönüm oranı, tüm burulma etkilerini ortadan kaldırmakta başarı sağlayamamıştır. Çalışmada üniform sönümleyici dağılımı kullanılmıştır. Bununla beraber optimizasyon yöntemleri kullanılarak daha iyi bir performans elde edilebileceği düşünülmektedir.

\section{Kaynaklar}

American Society of Civil Engineers ASCE 7-10, 2010. Minimum Design Loads For Buildings And Other Structures.

Bosco, M., Marino, E.M. and Rossi, P.P., 2013. An Analytical Method For The Evaluation Of The In-Plan Irregularity of Non-Regularly Asymmetric Buildings. Bull Earthquake Eng., 11, 1423-1445.

Constantinou, M.C., Soong, T.T. and Dargush, G.F., 1998. Passive Energy Dissipation Systems for Structural Design and Retrofit. Multidisciplinary Center for Earthquake Engineering Research, Buffalo NY.

DBYBHY, 2007. Deprem Bölgelerinde Yapılacak Binalar Hakkında Yönetmelik. T.C. Bayındırlık ve İskân Bakanlığı, 26454 Sayılı Resmi Gazete, Ankara.

Derdiman, M.K., Mirkelam, Z.A., 2011. Planında Asimetrik Betonarme Yapıların Deprem Davranışının Enerji Sönümleyicilerle İyileştirilmesi. Yapı Teknolojileri Elektronik Dergisi, 7, 2, 15-30.

Ebrahimi, A.H., Vazquez, P.M. and Baniotopoulos, C.C., 2017. Numerical studies on the effect of plan irregularities in the progressive collapse of steel structures. Structure and Infrastructure Engineering, 13, 1576-1583.

Fahjan, Y.M., 2008. Selecting and Scaling of Real Earthquake Records Appropriate the Acceleration Design Spectrum in Turkish Earthquake Code. IMO Technical Journal, 292, 4423-4444.

FEMA 273, 1997. Federal Emergency Management Agency Publication. NHRP Guidelines for the Seismic Rehabilitation of Buildings, Washington, D.C.

Goel, R.K., 1998. Effects of Supplemental Viscous Damping on Seismic Response of Asymmetric-Plan Systems. Earthquake Engineering and Structural Dynamics, 27, 125-141.

Han, S.W., Kim, T., Kim, D.H. and Baek, S.J., 2017. Seismic collapse performance of special moment steel frames with torsional irregularities, Engineering Structures, 141, 482-494. 
Hiçyılmaz, M., 2017. Yapısal Düzensizliğe Sahip Çelik Yapılarda Viskoz Sönümleyici Etkilerinin Araştırılması ve Yeni Bir Bağlantı Tipi Önerisi. Doktora Tezi, Eskişehir Osmangazi Üniversitesi Fen Bilimleri Enstitüsü, Eskişehir, 159.

International Building Code IBC06, 2006. International Code Council , USA

Işık, E., Özdemir, M. and Karaşin, İ.B., 2018. Performance Analysis of Steel Structures with A3 Irregularities. International Journal of Steel Structures, 18(3), 10831094.

Landi, L., Diotallevi, P.P., Castellari, G., 2013. On the Design of Viscous Dampers for the Rehabilitation of Plan-Asymmetric Buildings. Journal of Earthquake Engineering, 17, 1141-1161.

Lee, D., Taylor D.P., 2001. Viscous Damper Development and Future Trends. Structural Design of Tall Buildings, 10, 311-320.

Lin, W.H., Chopra, A.K., 2001. Understanding and Predicting Effects of Supplemental Viscous Damping on Seismic Response of Asymmetric One-Storey Systems. Earthquake Engineering And Structural Dynamics, 30, 1475-1494.

Mansoori, M.R., Moghadam, A.S., 2009. Using Viscous Damper Distribution to Reduce Multiple Seismic Responses of Asymmetric Structures. Journal of Constructional Steel Research, 65, 2176-2185.

Pacific Earthquake Engineering Research Center, 2006. PEER Strong Motion Database.

SAP2000, Versiyon 16.1.1, 2014. Yapısal Analiz Programı, Computers and Structures Inc., Berkeley-California.

Stefano, M., Pintucchi, B., 2008. A review of research on seismic behaviour of irregular building structures since 2002. Bull Earthquake Engineering, 6, 285-308.

TS500, 2000. Betonarme Yapıların Tasarım ve Yapım Kuralları. Türk Standartları Enstitüsü, Ankara, 83.

Ulucan, Z.Ç., Alyamaç, K.E., 2008. A3 düzensizliğine sahip yapıların doğrusal olmayan kat kesme kuvvetlerinin incelenmesi. Fırat Üniv. Fen ve Mühendislik Bilimleri Dergisi, 20(1), 145-155.

Uniform Building Code UBC97, 1997. Structural Engineering Design Provisions. International conference of building officials, Whittier, California. 